\title{
New derivatives of the antimalarial drug Pyrimethamine in the control of melanoma tumor growth: an in vitro and in vivo study
}

Chiara Tommasino ${ }^{1}$, Lucrezia Gambardella ${ }^{1}$, Maria Buoncervello ${ }^{3}$, Roger J. Griffin²^, Bernard T. Golding ${ }^{2}$, Manuela Alberton ${ }^{1}$, Daniele Macchia ${ }^{3}$, Massimo Spada $^{3}$, Bruna Cerbelli ${ }^{4}$, Giulia d'Amati ${ }^{4}$, Walter Malorni ${ }^{*}$, Lucia Gabriele ${ }^{3}$ and Anna Maria Giammarioli ${ }^{1}$

\begin{abstract}
Background: The antimalarial drug Pyrimethamine has been suggested to exert an antitumor activity by inducing apoptotic cell death in cancer cells, including metastatic melanoma cells. However, the dose of Pyrimethamine to be considered as an anticancer agent appears to be significantly higher than the maximum dose used as an antiprotozoal drug.

Methods: Hence, a series of Pyrimethamine analogs has been synthesized and screened for their apoptosis induction in two cultured metastatic melanoma cell lines. One of these analogs, the Methylbenzoprim, was further analyzed to evaluate cell-cycle and the mechanisms of cell death. The effects of Methylbenzoprim were also analyzed in a severe combined immunodeficiency (SCID)-mouse xenotransplantation model.
\end{abstract}

Results: Low dose of Methylbenzoprim was capable of inducing cytotoxic activity and a potent growth-inhibitory effect by arresting cell cycle in S-phase in melanoma cells. Methylbenzoprim was also detected as powerful antineoplastic agents in SCID-mouse although used at very low dose and as a single agent.

Conclusions: Our screening approach led to the identification of a "low cost" newly synthesized drug (methylbenzoprim), which is able to act as an antineoplastic agent in vitro and in vivo, inhibiting melanoma tumor growth at very low concentrations.

Keywords: Antimalarial Drugs, Chemotherapy, Antifolates, Apoptosis, Melanoma, Drug repurposing

Abbreviations: AV, Annexin-V; BrdU, Bromodeoxyuridine; BSA, Bovine serum albumin; CA-074-Me, Cathepsin B inhibitor; CQ, Chloroquine; DHFR, Dihydrofolate reductase; ECL, Enhanced chemiluminescence; Iso-Pyr, Iso-Pyrimethamine; LV, Leucovorin; MBP, Methylbenzoprim; MNP, M-nitropyrimethamine; MTS, 3-(4,5dimethylthiazol-2-yl)-5-(3-carboxymethoxyphenyl)-2-(4-sulfophenyl)-2H-tetrazolium; MZP, M-azidopyrimethamine; PBS, Phosphate-buffered saline; PI, Propidium iodide; PVDF, Polyvinylidene fluoride; Pyr, Pyrimethamine; SCID mice, severe combined immunodeficiency mice; SDS-PAGE, Sodium dodecyl sulfate polyacrylamide gel electrophoresis; TMZ, Temozolomide; z-VAD-fmk, Pan-caspase inhibitor

\footnotetext{
* Correspondence: malorni@iss.it; valter.malorni@iss.it

Deceased

'Department of Therapeutic Research and Medicine Evaluation, Section of Cell Aging and Degeneration, Istituto Superiore di Sanita, 00161 Rome, Italy Full list of author information is available at the end of the article
} 


\section{Background}

Metastatic melanoma has a poor prognosis and frequently develops resistance to standard therapies. Recently, new treatment options have been evaluated in the clinic and the results with immunotherapy and targeted therapy were promising [1]. Nevertheless, the initial excitement about the possibility of having discovered new effective approaches to treat melanoma has been followed by a degree of discouragement because these therapies are usually associated with high costs, side effects and none appears to be curative when used as a single agent $[2,3]$. Their efficacy may be enhanced in combination with other chemotherapeutic agents $[4,5]$. Actually, the drug dacarbazine, and its orally active analogue temozolomide (TMZ) remain the gold standard in melanoma chemotherapy. However, the response rate of melanoma to these drugs is approximately $20 \%$, underscoring the need to develop more effective treatments [6].

In this context, recent evidence has shown that antimalarial drugs could be beneficial in the treatment of different types of tumors [7, 8]. Pyrimethamine (2,4-diamino-5-pchlorophenyl-6-ethyl-pyrimidine; Pyr) is already used in humans as an orally administered drug for the treatment of infections caused by protozoan parasites (e.g. malaria and toxoplasma). Pyr belongs to the group of antifolate drugs inhibiting dihydrofolate reductase (DHFR), an enzyme, which is essential for the synthesis of folic acid, a cofactor for DNA synthesis [9]. DHFR inhibitors, e.g. methotrexate, have been studied for many years as anticancer agents since antifolates have greater selective toxicity toward rapidly dividing cells such as tumor cells. Previous studies have also demonstrated that Pyr is a potent pro-apoptotic inducer in cancer cells, e.g. in metastatic melanoma cells $[10,11]$. It has been suggested that the mechanism underlying this activity involves both the activation of the caspase cascade (e.g. caspases 8-9 and 3) and cathepsin cascade (e.g. cathepsin B). A remarkable inhibition of cell growth and a S-phase cell cycle arrest was also demonstrated.

Unfortunately, dose-related adverse effects of Pyr have been described since its introduction in the clinical practice, including bone marrow suppression with leukopenia, thrombocytopenia and megaloblastic anemia [12-15]. Although, some experimental studies suggested that a dose of $50 \mathrm{mg} /$ day of Pyr could be well tolerated [16, 17], clinical trials have also shown that unwanted effects are connected to the individual variability of patients. On these bases, Pyr should be used with caution in patients with impaired immune system, heart diseases and reduced renal or hepatic function. In regard to this, different studies have shown that the highest risks are found in individuals treated with Pyr at or above $50 \mathrm{mg} /$ day [15, 18-23]. According to the above described potential toxicity and taking into consideration the therapeutic potential of Pyr, as well as the demand for drug repositioning of low-cost agents such as Pyr $[24,25]$, a series of Pyr derivatives has been synthesized and screened for their activity on melanoma. We report here the results obtained in melanoma cultured cells and in xenografted animals that point at one of these Pyr-analogs, the MBP, as capable of hindering metastatic melanoma tumor growth at concentrations 10folds lower than Pyr.

\section{Methods \\ Cell lines}

Human metastatic melanoma cell lines MeWo and Mel501 were cultured in RPMI 1640 (Life Technologies, Invitrogen) supplemented with $10 \%$ heatinactivated fetal bovine serum (Euroclone), $2 \mathrm{mmol} / \mathrm{L}$ glutamine (Sigma-Aldrich, St. Louis, MO, USA) and $50 \mu \mathrm{g} / \mathrm{mL}$ gentamicin (Sigma). Tumor cells were tested as Mycoplasma-free (Mycoplasma detection kit; (Roche, Switzerland).

\section{Synthesis of Pyrimethamine analogues}

The target analogues were readily prepared from Pyrimethamine (Pyr) [26, 27]. Briefly, direct nitration of Pyr under standard condition afforded m-nitropyrimethamine (MNP) in near quantitative yield. Reduction of MNP to the corresponding amine, followed by diazotisation and treatment with sodium azide, gave $\mathrm{m}$-azidopyrimethamine (MZP). Conversion to the ethanesulfonate salt (MZPES) was achieved on treatment of MZP with aqueous ethanesulfonic acid. Methylbenzoprim (MBP) was synthesized from MNP in high yield by displacement of the 4-chloro substituent with $N$-benzylmethylamine employing 2ethoxyethanol as solvent. Iso-Pyrimethamine (Iso-Pyr) was synthesised by following the method of Russell and Hitchings [28]. Structural features of Pyr-analogs are shown in (Fig. 1).

\section{Chemicals and drugs}

Pyr (Sigma), Pyr-analogues indicated above and TMZ (Sigma) were dissolved in DMSO (no precipitation of drug was observed on addition of the DMSO solution to aqueous medium); Leucovorin (Sigma) and Chloroquine (CQ) (Sigma) were dissolved in water and were diluted in RPMI 1640 immediately before experiments. The cathepsin B inhibitor CA-074-Me (Calbiochem, Millipore, Germany) and pan-caspase inhibitor z-VAD-fmk (R\&D System, USA) were diluted in RPMI 1640 immediately before experiments.

\section{Treatments}

Melanoma cells were exposed to Pyr $(8 \mu \mathrm{g} / \mathrm{ml})$, TMZ (100 $\mu \mathrm{mol} / \mathrm{L})$, Pyr-analogues $(0.8,8,80 \mu \mathrm{g} / \mathrm{ml})$ for 24,48 and $72 \mathrm{~h}$. In the combined treatments, Leucovorin (LV) 
<smiles>CCc1nc(N)nc(N)c1-c1ccc(Cl)cc1</smiles>

\section{Pyrimethamine (Pyr)}<smiles>CCc1nc(N)nc(N)c1-c1cccc(Cl)c1</smiles>

Iso-Pyrimethamine (Iso-Pyr)<smiles>CCc1nc(N)nc(N)c1-c1ccc(N(C)Cc2ccccc2)c(N(C)Cc2ccccc2)c1</smiles><smiles>Nc1nc(N)c(-c2ccc(Cl)c(N3CCCC3)c2)c(N)n1</smiles>

m-Nitropyrimethamine (MNP)

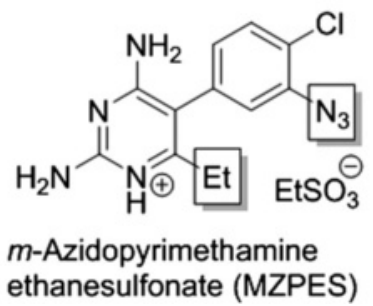

Fig. 1 Chemical structures. Structures of Pyrimethamine (Pyr), Iso-Pyrimethamine (Iso-Pyr), m-Nitropyrimethamine (MNP), Methylbenzoprim (MBP) and $m$-Azidopyrimethamine ethanesulfonate salt (MZPES). Structural differences in Pyrimethamine analogues are highlighted by boxes

$(10 \mu \mathrm{g} / \mathrm{ml})$ was given at the same time points of the above drugs; CQ $(10 \mu \mathrm{M})$ was given $16 \mathrm{~h}$ before the treatment with Pyr or MBP; the cathepsin B inhibitor (CA-074-Me, $10 \mu \mathrm{mol} / \mathrm{L}$ ) and the pan-caspase inhibitor z-VAD-fmk $(50 \mu \mathrm{mol} / \mathrm{L})$ were added to the culture medium $2 \mathrm{~h}$ before the treatment.

\section{Cell viability assay}

CellTiter 96 AQueous One Solution Cell Proliferation Assay (Promega, Madison, WI) was used to determine cytotoxic effects resulting from treatment with drugs. Melanoma cells were plated at a density of $3 \times 10^{3}$ cells/ well in 96-well plates, and then treated with various concentrations of MBP and Pyr for 24, 48, and $72 \mathrm{~h}$. At the end of the treatment period, $20 \mu \mathrm{l}$ of 3-(4,5-dimethylthiazol-2-yl)-5-(3-carboxymethoxyphenyl)-2-(4-sulfophenyl)-2 $H$-tetrazolium (MTS) reagent were added to each well. The plates were incubated for $30 \mathrm{~min}$ at $37^{\circ} \mathrm{C}$ in the dark. Absorbance at $450 \mathrm{~nm}$ was determined on Opsys MR spectrophotometer (DYNEX Technologies, Denkendorf, Germany) using Windows Revelation QuickLink software. Each experimental condition was performed in triplicate and repeated at least twice. All values were normalized with respect to the viability of untreated cells.

\section{Cell death evaluation}

Quantitative evaluation of apoptosis was performed by a double staining flow cytometry method using FITCconjugated Annexin V (AV)/propidium iodide (PI) apoptosis detection kit (Marine Biological Laboratory, MBL, USA) according to the manufacturer's protocol. Reported data refer to both early $\left(\mathrm{AV}^{+} / \mathrm{PI}^{-}\right.$cells, still alive) and late $\left(\mathrm{AV}^{+} / \mathrm{PI}^{+}\right.$cells, dead cells) apoptotic melanoma cells.

\section{Western blotting analysis}

Cell lines were lysed in RIPA buffer (100 mM Tris-HCL $\mathrm{pH} 8,150 \mathrm{mM} \mathrm{NaCl}, 1 \%$ Triton X-100, $1 \mathrm{mM} \mathrm{MgCl}$, $25 \mathrm{mM} \mathrm{NaVO}_{4}$ ) in the presence of complete proteaseinhibitor mixture (Sigma). Immunoblotting was performed with antibodies to: caspase-9 (rabbit polyclonal antibody, Enzo Life Sciences); caspase-8 (mouse monoclonal antibody, Transduction Laboratories); caspase-3 (mouse monoclonal antibody, Enzo Life Sciences); cathepsin B (rabbit polyclonal antibody, Calbiochem). As a control, the membranes were incubated with specific antibodies of anti- $\alpha$-tubulin (mouse monoclonal antibody, Sigma). The intensities of bands of active fragments were quantified normalizing to Tubulin. The optical density of the bands [integrated area in arbitrary units (AU)] was measured by using the National Institutes of Health Image J software (rsb.info.nih.gov/ij). 


\section{Cathepsin B}

Anti-cathepsin B polyclonal antibody (Calbiochem) was used to evaluate the expression of activated cathepsin B by flow cytometry analysis. Control and treated cells were fixed with $4 \%$ paraformaldehyde in phosphatebuffered saline (PBS) for $30 \mathrm{~min}$ at room temperature. After washing in the same buffer, cells were permeabilized with 0.5 Triton X-100 (Sigma) in PBS for 5 min. Then cells were incubated with Anti-cathepsin B polyclonal antibody (Calbiochem) and after $30 \mathrm{~min}$ at $37{ }^{\circ} \mathrm{C}$, cells were washed and then incubated with anti-rabbit fluorescein-linked whole antibodies (Molecular Probes, Eugene, OR, USA).

\section{Caspase activity}

Caspase-9, caspase-8 and caspase-3 activities were assayed by using the CaspGLOW fluorescein active caspase staining kit (MBL), following the manufacturer's instruction, as previously described [18]. Western blot was performed as described above.

\section{Cell cycle analysis}

Cultured cells were treated with $1 \mathrm{mmol} / \mathrm{L}$ bromodeoxyuridine (BrdU; BD Immunocytometry Systems) for $30 \mathrm{~min}$, removed from culture and fixed in $70 \%$ ice-cold ethanol. $1 \times 10^{6}$ fixed cells were incubated in $3 \mathrm{~N} \mathrm{HCl}$ for $20 \mathrm{~min}$. After washing with $0.1 \mathrm{~mol} / \mathrm{L} \quad \mathrm{Na}_{2} \mathrm{~B}_{4} \mathrm{O}_{7}$ (pH 8.5) to stop acid denaturation, cells were washed twice with $1 \%$ bovine serum albumin and $0.5 \%$ Tween 20 and labeled with an anti-BrdU FITC-conjugated (BD Immunocytometry Systems) for $30 \mathrm{~min}$ at $4{ }^{\circ} \mathrm{C}$. Cells were then stained with $40 \mu \mathrm{g} / \mathrm{mL}$ PI (Sigma) in the presence of $10 \mu \mathrm{mol} / \mathrm{L}$ RNase (Sigma) for $30 \mathrm{~min}$ at $37^{\circ} \mathrm{C}$ followed by analysis on a flow cytometer.

\section{Analysis of autophagy}

Detection of autophagy was performed by using Cyto-ID Autophagy Detection Kit (Enzo Life Sciences, Lausen Switzerland). The kit was optimized for detection of autophagy in live cells by flow cytometry. CYTO-ID ${ }^{\circ} \mathrm{Au}-$ tophagy Detection Kit measures autophagic vacuoles and monitors autophagic flux in lysosomally inhibited live cells using a dye that selectively labels accumulated autophagic vacuoles [29]. The probe is a cationic amphiphilic tracer (CAT) dye that rapidly partitions into cells in a similar manner as drugs that induce phospholipidosis. Careful selection of titratable functional moieties on the dye prevents its accumulation within lysosomes, but enables labeling of vacuoles associated with the autophagy pathway. Induction of autophagic flux can be visualized by enhanced accumulation of autophagic vesicles if lysosomal function is inhibited, preventing removal of these vesicles.
This assay provides a rapid, specific and quantitative approach for monitoring autophagic activity at the cellular level by using a $488 \mathrm{~nm}$-excitable probe that becomes fluorescent in vesicles produced during autophagy. Western blot was also performed, as described above.

\section{Animals}

CB.17 SCID/SCID female mice (Harlan Italy) were used at 4 to 5 weeks of age and were kept under specific pathogen-free conditions as previously described [11]. Before injection of Mycoplasma-free melanoma cells, mice were weighed and divided into two control groups (untreated and DMSO-treated) and two treatment groups (Pyr and MBP) with eight mice per group. Mice were injected s.c. into the right flank with $2 \times 10^{6}$ melanoma Mel501 cells per mouse. Suspensions of Pyr (45 mg/kg) were prepared daily in $5 \%$ of DMSO in aqueous methylcellulose solution and the suspensions of MBP $(12 \mathrm{mg} / \mathrm{Kg})$ in $5 \%$ of DMSO. At the onset of tumor (i.e. $5 \mathrm{~d}$ from melanoma cell injection), mice were given by oral gavage with the same volume $(200 \mu \mathrm{L})$ of vehicle or Pyr $(45 \mathrm{mg} / \mathrm{kg})$ or MBP $(12 \mathrm{mg} /$ $\mathrm{Kg}) 5 \mathrm{~d}$ per week up to $40 \mathrm{~d}$ from injection (35 d of drug administration). All mice were inspected daily and the overall clinical condition was assessed. Tumor growth was monitored by measuring maximal and minimal diameters by caliper and tumor weight was estimated with the formula: tumor weight $(\mathrm{mg})$ $=\left[\right.$ length $(\mathrm{mm}) \times$ width $\left.^{2}(\mathrm{~mm})\right] / 2$. Procedures and facilities followed the requirements of Commission Directive 86/609/EEC concerning the protection of animals used for experimental and other scientific purposes. Italian legislation is defined in D.L. no. 116 of January 27, 1992.

\section{Histological analysis}

Livers were formalin-fixed and paraffin embedded. Consecutive sections (5-6 $\mu \mathrm{m}$ thick) were stained with hematoxylin-eosin and observed under a light microscope (Olympus Corporation of the Americas, Center Valley, USA).

\section{Statistical analyses}

All samples were analyzed with a FACSCalibur cytometer (BD, Biosciences, Heidelberg, Germany) equipped with a 488 argon laser. At least 20,000 events were acquired. Data were recorded by a Macintosh computer using CellQuestPro Software (BD). Statistical analyses were performed by using Student's $t$-test for paired samples or non-parametric Anova test. All data reported were verified in at least three different experiments and reported as mean \pm S.D. $P$-values $<0.05$ were considered as statistically significant. 


\section{Results}

Pyrimethamine analogues induce apoptosis in human melanoma cell lines

It has already been shown that Pyr is a potent apoptosis inducer in cancer cells [8-11, 17]. Thus, we first evaluated the apoptosis-inducing potential of Pyr-analogues in two human metastatic melanoma cell lines (MeWo and Mel501) by using annexin V/propidium iodide (AV/ PI) double staining assay. Parallel analyses were carried out in cells treated with Pyr and the chemotherapeutic agent TMZ at a clinically relevant concentration
(100 $\mu \mathrm{mol} / \mathrm{L})$ [30]. We tested Pyr-analogues using the same dosage of Pyr $(8 \mu \mathrm{g} / \mathrm{ml})$, which is known to induce cell death in melanoma cells $[10,11]$ at different time points, i.e. after 24, 48 and $72 \mathrm{~h}$ of treatment. In addition, lower and higher doses (10-fold lower or higher) were also evaluated. In Fig. 2, we reported the percentage of annexin V-positive cells (apoptotic cells) detected in the two cell lines. All screened compounds were able to induce apoptosis, but only one of these was more potent than Pyr and TMZ. In particular, the compound MBP was able to induce apoptosis even at 10-

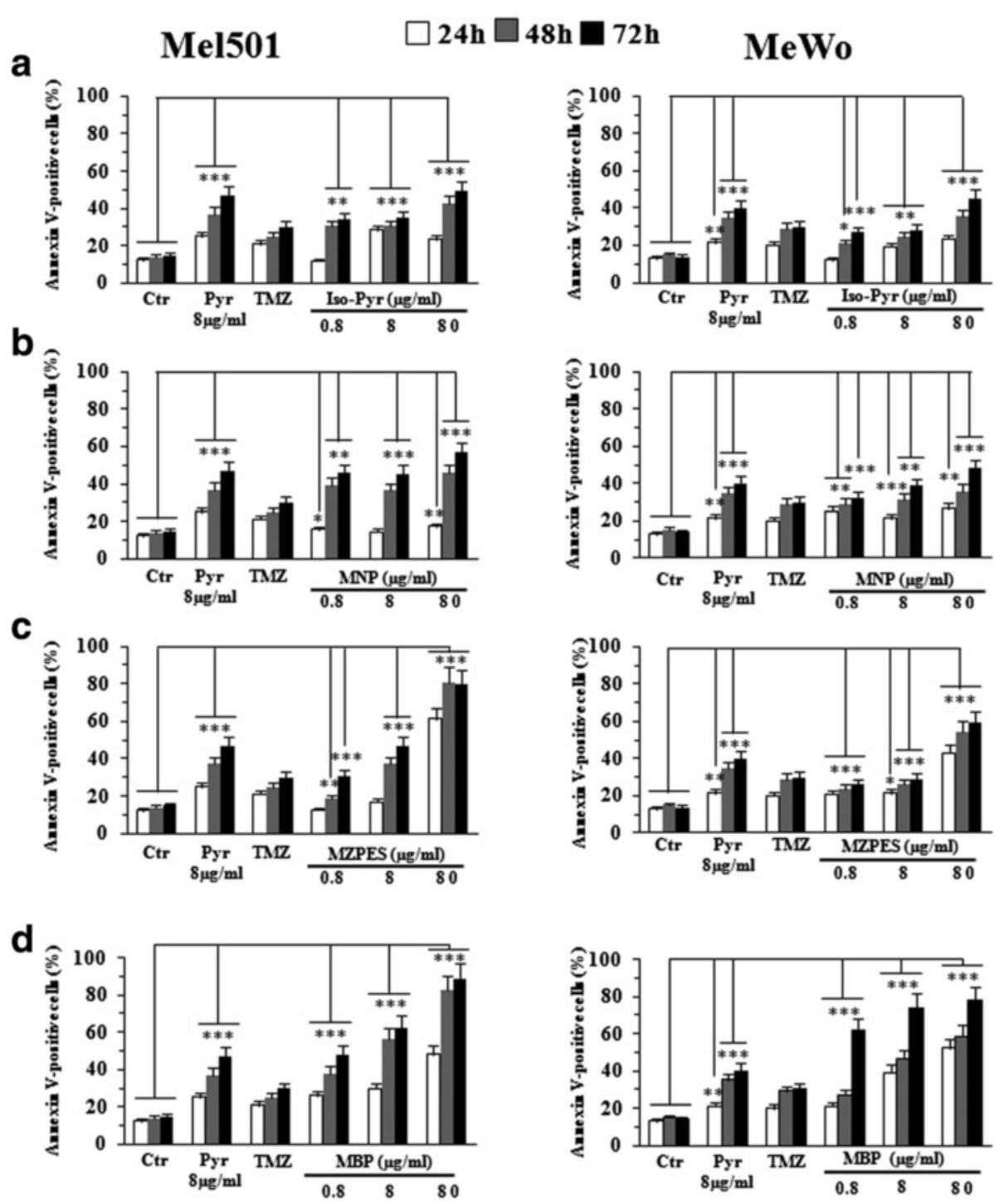

Fig. 2 Proapoptotic effects of Pyr-analogues versus Pyrimethamine and temozolomide on Mel501 and MeWo cell lines. Flow cytometric analysis of apoptosis after the treatment with Pyr $(8 \mu \mathrm{g} / \mathrm{ml})$, TMZ $(100 \mu \mathrm{mol} / \mathrm{L})$ and Pyr-analogues $(0.8,8,80 \mu \mathrm{g} / \mathrm{ml})$ for 24, 48 and $72 \mathrm{~h}$ on Mel501 (left panels) and MeWo (right panels) cell lines. Columns, mean values of 10 independent experiments; bars, SD. ${ }^{*}, P<0.05$; ${ }^{* *}, P<0.01,{ }^{* * *} P<0.001$ significance compared with untreated cells. All screened compounds, Iso-Pyr (a), MNP (b), MZPES (c) and MBP (d), were able to induce apoptosis but only one of these, MBP $(\mathbf{d})$, was more potent than Pyr and TMZ even at very low concentration $(0.8 \mu \mathrm{g} / \mathrm{ml})$ in both cell lines. Note the significant difference between MBP-treated and TMZ-treated samples after 48 and $72 \mathrm{~h}$ even at lower concentration of MBP $(0.8 \mathrm{\mu g} / \mathrm{ml})$ 
Table 1 Single-color staining with Propidium iodide

\begin{tabular}{|c|c|c|c|c|c|c|}
\hline Mel501 & Ctr & Pyr & Temozolomide & MBP $0.8 \mathrm{ug} / \mathrm{ml}$ & MBP $8 u g / m l$ & MBP 80ug/ml \\
\hline $24 \mathrm{~h}$ & 0.4 & 1 & 0.1 & 0.6 & 2 & 11.5 \\
\hline $48 \mathrm{~h}$ & 1.2 & 4 & 4 & 2 & 3.6 & 14 \\
\hline $72 \mathrm{~h}$ & 1 & 3.6 & 3 & 2.4 & 4.2 & 25 \\
\hline MeWo & Ctr & Pyr & Temozolomide & MBP $0.8 \mathrm{ug} / \mathrm{ml}$ & MBP 8ug/ml & MBP $80 \mathrm{ug} / \mathrm{ml}$ \\
\hline $24 \mathrm{~h}$ & 0.5 & 1 & 0.8 & 0.9 & 0.9 & 9.5 \\
\hline $48 \mathrm{~h}$ & 0.8 & 0.5 & 1 & 1.6 & 1.4 & 15 \\
\hline $72 \mathrm{~h}$ & 1 & 0.7 & 0,8 & 1 & 1 & 18 \\
\hline
\end{tabular}

Numbers in the columns represent the average percentage of AV negative/PI positive (necrotic cells) obtained by 10 different experiments

fold lower concentration $(0.8 \mu \mathrm{g} / \mathrm{ml})$ in both cell lines (Fig. 2d, left and right panels). Of note, for all tested concentrations, the percentage of necrotic cells (AV-/ PI + cells) was below $4 \%$ with the exception of the higher dose of MBP $(80 \mu \mathrm{g} / \mathrm{ml})$, which induced high levels of PI single positive cells (necrotic cells) in both cell lines at all time points tested (Table 1). On the basis of the screening reported above, the MBP compound was selected for further, more detailed analyses using the 0.8 and $8 \mu \mathrm{g} / \mathrm{ml}$ doses.

\section{MTS cell viability assay and determination of the $\mathrm{IC}_{50}$ of Methylbenzoprim}

Since the newly synthesized compound MBP appears to be effective at lower doses than Pyr, we evaluated it in vitro $\mathrm{IC}_{50}$ value versus that of Pyr by MTS assay in both Mel501 and MeWo cell lines. Treatment of the two human melanoma cell lines was performed for 24, 48 and $72 \mathrm{~h}$ at concentrations ranging between 0.8 and $64 \mu \mathrm{g} / \mathrm{ml}$. As shown in Fig. 3, a significant higher suppression of cell growth by MBP versus Pyr was observed in both types of

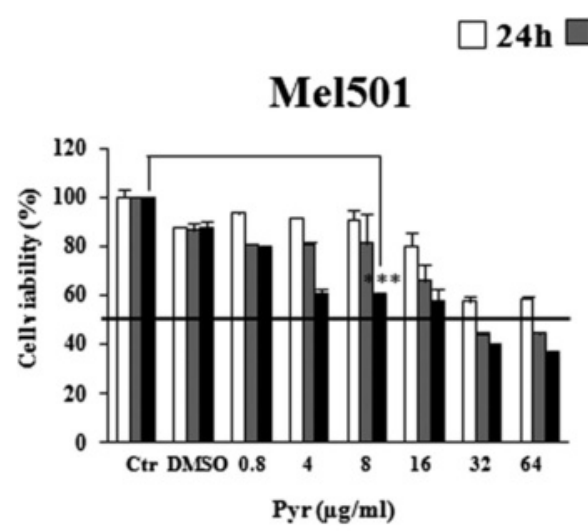

$48 \mathrm{~h} \square 72 \mathrm{~h}$
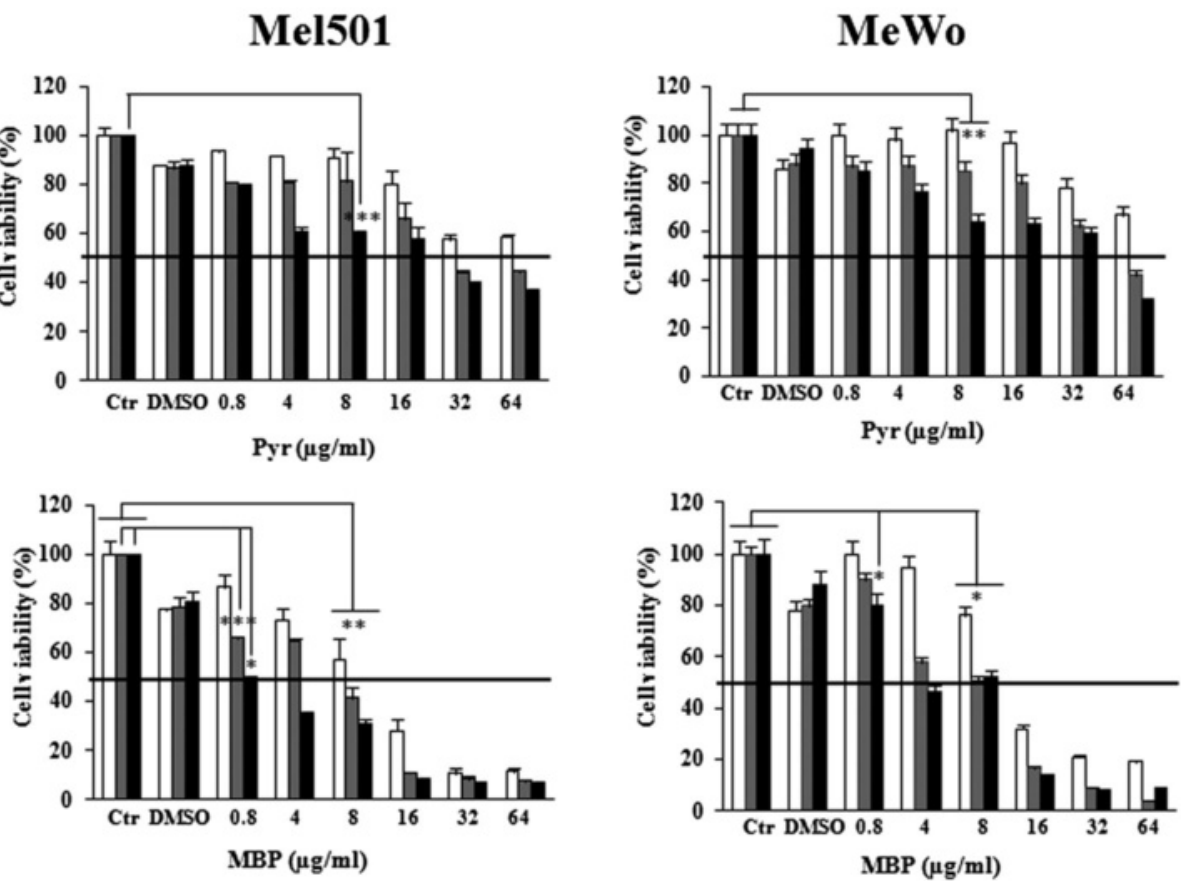

Fig. 3 Antiproliferative effects of Methylbenzoprim and Pyrimethamine on Mel501 and MeWo cell lines. Viability of drug-treated Mel501 (left) and MeWo (right) cell lines was evaluated at 24, 48 and $72 \mathrm{~h}$ by MTS assay. Each value is normalized to untreated cells. Data are the means \pm S.D. of three independent experiments bars, SD. ${ }^{*}, P<0.05$; ${ }^{*}, P<0.01$, *** $P<0.001$ significance compared with untreated cells. We observed a timeand dose-dependent decrease of cell proliferation in Pyr and MBP treated cells, but at different doses (from 0.8 to $64 \mu \mathrm{g} / \mathrm{ml}$ ). In particular, after $72 \mathrm{~h}$ of exposure Mel501 showed an $\mathrm{IC}_{50}$ of $0.8 \mathrm{\mu g} / \mathrm{ml}$ for MBP, indicating a much higher activity of this agent with respect to Pyr, characterized by an $I_{50}$ ranging between 16 and $32 \mu \mathrm{g} / \mathrm{ml}$. Similarly, MeWo cells resulted in much more susceptibility to the antiproliferative effects of MBP, since the $\mathrm{IC}_{50}$ of this agent ranged between 4 and $8 \mu \mathrm{g} / \mathrm{ml}$ as compared with that of Pyr $(32-64 \mu \mathrm{g} / \mathrm{ml}$ ) 
cancer cells. Although for both drugs we observed a time and dose-dependent inhibition of cell proliferation, this event occurred earlier and at lower doses when cells were treated with MBP. In particular, MBP showed higher cytotoxic potential against Mel501 cells with $\mathrm{IC}_{50}=0.8 \mu \mathrm{g} / \mathrm{ml}$ after $72 \mathrm{~h}$ of exposure, with respect to Pyr, characterized by $\mathrm{IC}_{50}$ ranging between 16 and $32 \mu \mathrm{g} / \mathrm{ml}$. Similarly, MeWo cells resulted in much more susceptibility to the anti-proliferative effects of MBP, since, after $72 \mathrm{~h}$, the $\mathrm{IC}_{50}$ of this agent ranged between 4 and $8 \mu \mathrm{g} / \mathrm{ml}$ as compared with that of Pyr $(32-64 \mu \mathrm{g} / \mathrm{ml})$.

\section{Methylbenzoprim induces cathepsin B and caspase dependent apoptosis on melanoma cells}

In previous studies we showed Pyr induced apoptosis in melanoma cells via a mechanism that brought into play both the caspase and cathepsin cascades [11]. To identify the apoptotic pathway being activated in response to

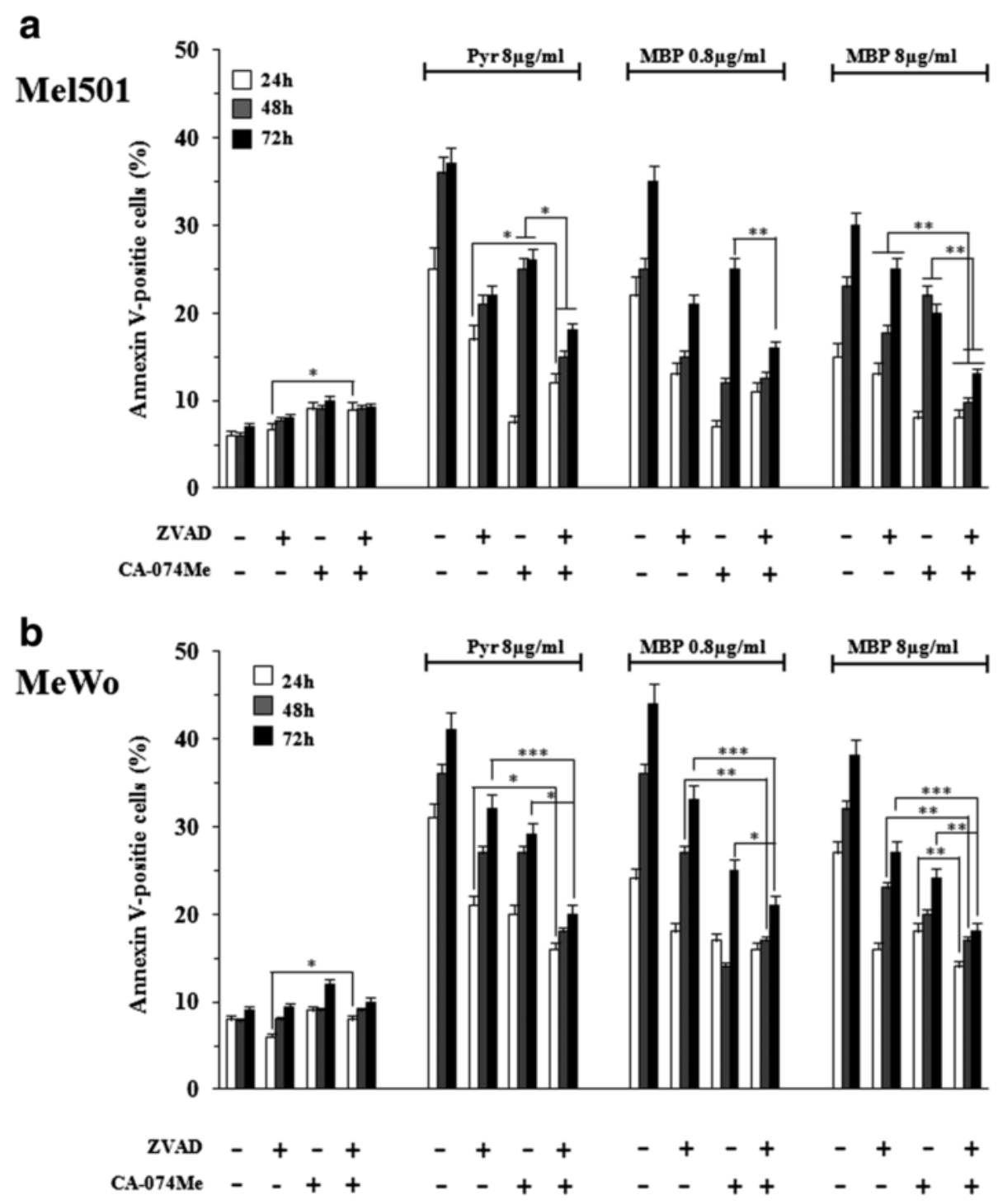

Fig. 4 Pan-caspase inhibitor Z-VAD-FMK and the cathepsin B inhibitor CA-074-Me inhibit Methylbenzoprim-induced apoptosis in melanoma cells. The percentage of apoptotic cells was evaluated after 24,48 and $72 \mathrm{~h}$ of $\mathrm{MBP}(0.8,8 \mu \mathrm{g} / \mathrm{ml})$, the positive control Pyr $(8 \mu \mathrm{g} / \mathrm{ml})$ and untreated cells in Mel501 (panel a) and MeWo (panel b) cell lines pretreated for $2 \mathrm{~h}$ with the pan-caspase inhibitor Z-VAD-FMK (50 $\mu$ mol/L) or the cathepsin B inhibitor CA-074-Me $(10 \mu \mathrm{mol} / \mathrm{L})$ or both. Columns, mean values of three independent experiments; bars, SD. ${ }^{*}, P<0.05 ;{ }^{* *}, P<0.01,{ }^{* * *} P<0.001$ significance compared with Pyr and MBP treated cells. Z-VAD-FMK induced a protective effect in a time dependent manner in Mel501 and MeWo cell lines (panels $\mathbf{a}$ and $\mathbf{b}$, respectively). When cathepsin B inhibitor CA-074-Me was used, apoptosis was significantly abrogated after $24 \mathrm{~h}$ treatment; this effect persisted after 48 h, while it was less evident after 72 h. Z-VAD-FMK and CA-074-Me, administered simultaneously, increased protective effect in both cell lines at all time points analyzed (panels $\mathbf{a}$ and $\mathbf{b}$ ) 


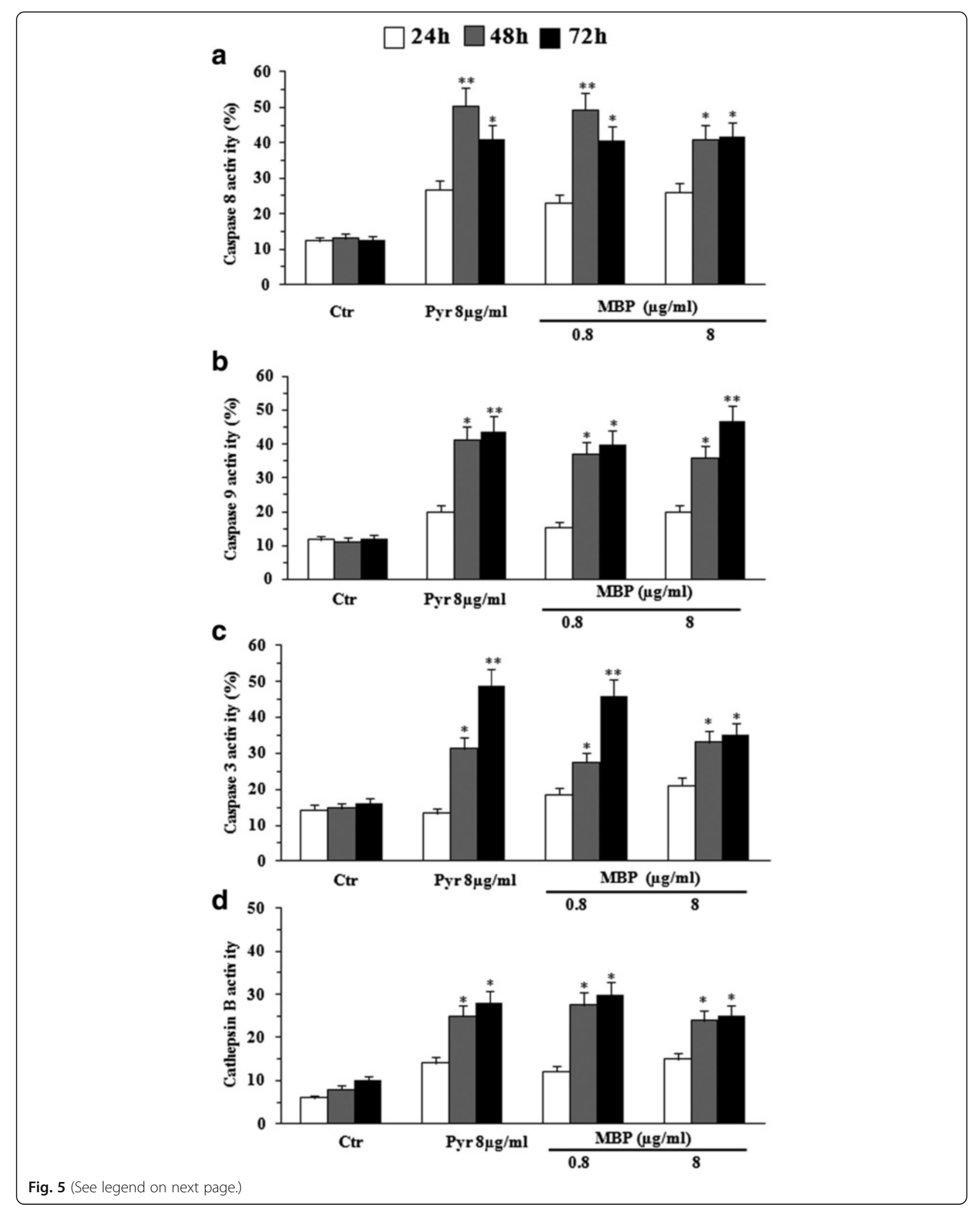


(See figure on previous page.)

Fig. 5 Flow cytometric analysis of apoptotic proteases. The activation of caspases 8, caspase 9, caspase 3 and cathepsin B were evaluated at 24, 48 and $72 \mathrm{~h}$ of Pyr $(8 \mu \mathrm{g} / \mathrm{ml})$ and $\operatorname{MBP}(0.8,8 \mu \mathrm{g} / \mathrm{ml})$ treatment on Mel501 cells. Both caspases $(8,9$ and 3$)$ and cathepsin B are involved in MBP induced apoptosis. Flow cytometric data showed: i) a significant increase of caspase- 8 activity starting from $24 \mathrm{~h}$, reaching a peak at 48 and the plateau at $72 \mathrm{~h}$ (a); ii) activation of caspase- 9 and caspase-3 after 48 and $72 \mathrm{~h}$ treatment ( $\mathbf{b}$ and $\mathbf{c}$ ); iii) a significant increase of expression cathepsin B starting from $48 \mathrm{~h}$, which persisted at later time points (72 h) (d), after MBP treatment $(0.8 \mu \mathrm{g} / \mathrm{ml})$. The higher dose of MBP ( $8 \mu \mathrm{g} / \mathrm{ml})$ did not induce more relevant effects on the above proteases. Columns, mean values of three independent experiments; bars, SD. ${ }^{*}, P<0.05$; ${ }^{* *}, P<0.01 ;$ significance compared with untreated cells

MBP (the caspase, the cathepsin pathway or both), Mel501 and MeWo cell lines were initially pre-treated with: i) the pan-caspase inhibitor Z-VAD-FMK and ii) the cathepsin B inhibitor CA-074-Me, at different time points (Fig. 4a and b). Consistent with our previous study [11], pan-caspase (z-VAD-fmk) and cathepsin B (CA-074-Me) inhibitors exerted protective effects at all time points studied in both Mel501 (Fig. 4a) and MeWo (Fig. 4b) cell lines. In particular, z-VAD-fmk induced a protective effect in a time-dependent manner in both cell lines (Fig. 4a and b). Interestingly, the observed effects were equally powerful at both low and high dosages of $\operatorname{MBP}(0.8,8 \mu \mathrm{g} / \mathrm{ml})$. Similarly, when cathepsin B inhibitor CA-074-Me was used (Fig. 4a and b), apoptosis was significantly abrogated after $24 \mathrm{~h}$ of treatment and this effect persisted after $48 \mathrm{~h}$ but was less evident after $72 \mathrm{~h}$. When caspase and cathepsin B inhibitors were administered simultaneously, cell death appeared much more inhibited in both cell lines at all time points analyzed (Fig. 4a and b).

In consideration of overlapping results in the two tested melanoma cell lines, hereafter only data obtained with the Mel501 cell line will be reported. The experiments that follow were performed by comparing the effects induced by both dosages of $\operatorname{MBP}(0.8,8 \mu \mathrm{g} / \mathrm{ml})$ with Pyr $(8 \mu \mathrm{g} / \mathrm{ml})$ (Fig. 5). Hence, in accord with apoptosis inhibition results reported above, we next examined the possible involvement of caspases in the antitumor effects of MBP by both flow cytometric (Fig. 5) and Western blot analyses (Fig. 6): the upstream caspases caspase-8, (mainly involved in receptor-mediated apoptosis) and caspase-9 (mainly involved in mitochondriamediated apoptosis): caspase-3 (an executioner caspase); the lysosomal protease cathepsin $\mathrm{B}$. The lower dose of MBP $(0.8 \mu \mathrm{g} / \mathrm{ml})$ showed effects comparable to that of Pyr at $8 \mu \mathrm{g} / \mathrm{ml}$, whereas the higher dose of MBP $(8 \mu \mathrm{g} / \mathrm{ml})$ did not induce more relevant effects. In particular, flow cytometric data showed a significant increase of caspase- 8 activity starting from $24 \mathrm{~h}$, reaching a peak at $48 \mathrm{~h}$ and the plateau at $72 \mathrm{~h}$ (Fig. $5 \mathrm{a}$ ) whereas the activation of caspase9 and caspase- 3 was detected after treatment for 48 and $72 \mathrm{~h}$ (Fig. 5b and c). The representative histograms have been provided as Additional file 1: Figure S.1A and S.1B. Flow cytometric data also showed a significant increase of cathepsin B activity starting from $48 \mathrm{~h}$, which persisted at later time points (72 h) (Fig. 5d). The representative histograms have been provided as Additional file 1: Figure S.2A and S.2B. Western Blot (Fig. 6 left panels) and densitometric analysis (Fig. 6 right panels) confirmed these results by showing an early activation of caspase 8 , whereas caspase 9, caspase 3 and Cathepsin B activation occurred at later time points.

Taken together, these experiments suggest that MBP induces pro-apoptotic effects, mediated by both caspaseand cathepsin-dependent pathways, at a significantly lower dose than Pyr $(0.8 \mu \mathrm{g} / \mathrm{ml}$ and $8 \mu \mathrm{g} / \mathrm{ml}$, respectively).

\section{Methylbenzoprim induces S-phase cell cycle arrest}

To further investigate the effects induced by low dose of MBP, Mel501 cell cultures were treated with MBP and Pyr as described above and then analyzed for cell cycle distribution. As shown in Fig. 7, both Pyr and MBP hampered cell cycle progression by arresting the cells in $S$-phase; a corresponding decrease of cells in the $G_{1}$ and $\mathrm{G}_{2}-\mathrm{M}$ phases was also observed. In particular, the low dose of MBP was sufficient to induce a high proportion of cells in S-phase as compared to Pyr (Fig. 7b). The formation of a hypodiploid sub-G1 peak (indicative of cell loss due to apoptosis) was also detected (Additional file 1: Figure S2), confirming the data already evaluated by AV/PI double staining assay (see Fig. 2).

Taken together, these data suggest that a low dose of MBP is able to induce both cell cycle arrest and cell loss due to apoptosis leading to marked antiproliferative effects.

\section{Dihydrofolate reductase activity}

Pyr belongs to the group of antifolate drugs blocking the enzyme dihydrofolate reductase (DHFR) that is essential for the synthesis of folic acid, a cofactor required for DNA synthesis. Previous studies reported that Pyr effects are mainly mediated by its antifolate activity in melanoma cells [10]. To investigate whether the antifolate activity of MBP could contribute to its antiproliferative effects in melanoma cells, we tested the apoptosis-inducing potential of MBP in the Mel501 cell line pre-treated with the reduced form of folate Leucovorin ( $\mathrm{LV}, N^{5}$-formyltetrahydrofolate), a drug widely used to counteract the effects of antifolates [31]. In these experiments, Mel501 cell lines were treated with LV alone and in combination with Pyr $(8 \mu \mathrm{g} / \mathrm{ml})$ and 

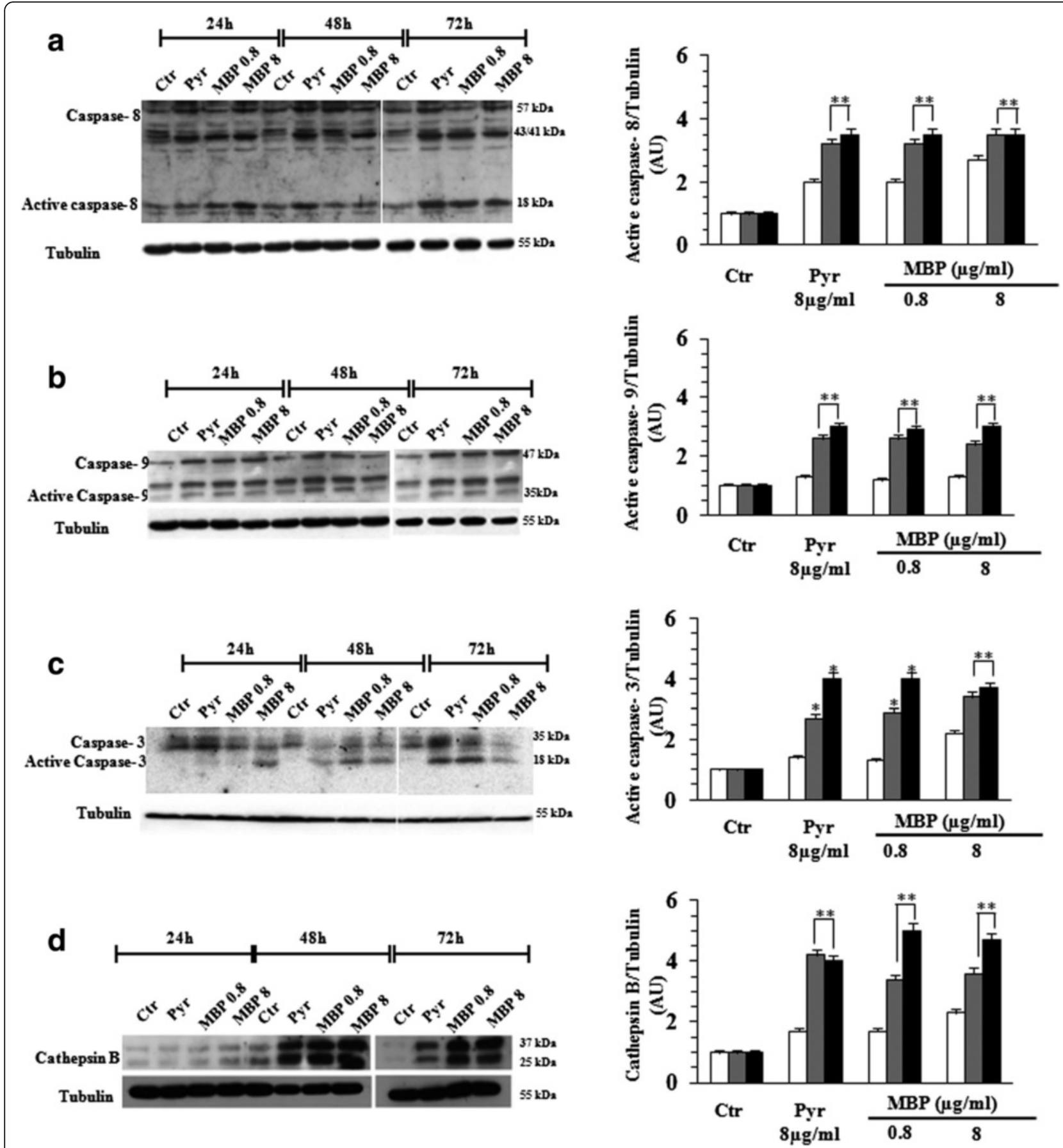

Fig. 6 Western Blot analysis of apoptotic proteases. Western Blot analysis confirmed the activation of apoptotic proteases in Mel501 cells treated with Pyr $(8 \mu \mathrm{g} / \mathrm{ml})$ and MBP $(0.8,8 \mu \mathrm{g} / \mathrm{ml})$. Note that procaspase-8 $(57 \mathrm{kDa})$ is early cleaved into the intermediate forms p43 and p41 and finally processed to the active p18 subunit (Fig. 5a, left panel), and procaspase $9(47 \mathrm{kDa})$ is cleaved in $35 \mathrm{kDa}$ subunit (Fig. 5b, left panel). The cleavage of caspase 3 (17 kDa) (Fig. 5c, left panel) and Cathepsin B (25 kDa) (Fig. 5d, left panel) occurred at later time points. The intensities of bands of active caspase fragments were quantified by densitometric analysis (Fig. $6 \mathbf{a}$-d right panels). The values were normalized to Tubulin and expressed as arbitrary units (AU). Columns, mean of three independent experiments; bars, SD. ${ }^{*}, P<0.05$; ${ }^{* *}, P<0.01$

MBP $(0.8 \mu \mathrm{g} / \mathrm{ml})$, after which apoptotic cell death was evaluated.

As shown in Fig. 8a, LV abrogated significantly apoptosis at all time points upon MBP treatment whereas was only partly able to counteract the apoptotic effects induced by Pyr. Since we showed that MBP increased expression of caspases (Fig. 5) and folate deficiency has been suggested to increase the expression of caspases 


\section{Mel501}

\section{$\square \mathrm{G0/G1} \quad \square \mathrm{s} \quad \square \mathrm{G} 2 \mathrm{M}$}

$24 h$

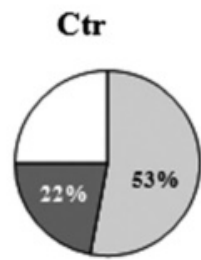

$48 \mathrm{~h}$

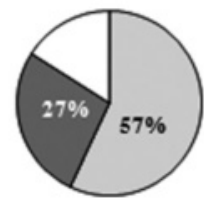

$72 \mathrm{~h}$

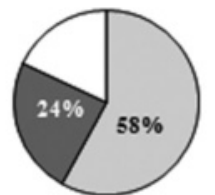

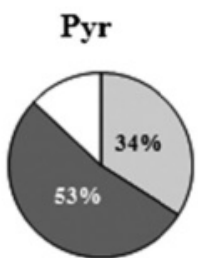
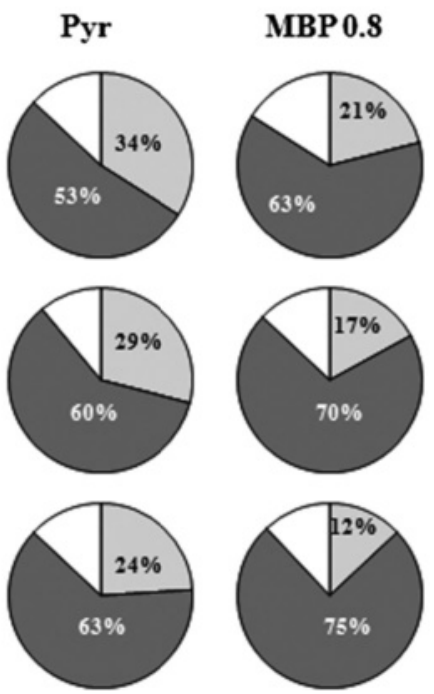

MBP 8
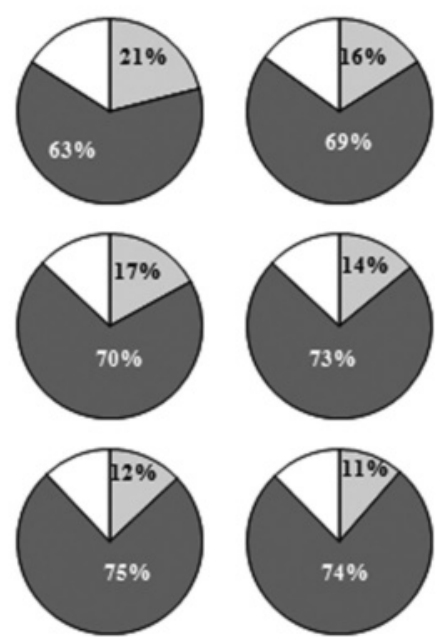

Fig. 7 Methylbenzoprim induces S-phase cell cycle arrest. Cell-cycle distribution was evaluated by flow cytometric analysis on Mel501 proliferating cells treated with Pyr $(8 \mathrm{\mu g} / \mathrm{ml})$ and MBP $(0.8,8 \mu \mathrm{g} / \mathrm{ml})$ for 24,48 and $72 \mathrm{~h}$. Pie charts show the distribution of cells in the different each phase of the cell cycle: S-phase (dark grey), G2/M (white) and G0/G1 (grey), obtained from three independent experiments. In particular, the low dose of MBP $(0.8 \mu \mathrm{g} / \mathrm{ml})$ was sufficient to induce a high percentage of cells in S-phase as compared to high dose of Pyr $(8 \mu \mathrm{g} / \mathrm{ml})$ at all time points analyzed. The representative histograms have been provided as Additional file 1: Figure S.3

[32], we also analyzed the effects of LV on expression of apoptotic proteases in melanoma cells treated with MBP as compared to Pyr. Interestingly, the increased expression of caspase 8 (Fig. 8b), caspase 9 (Fig. 8c) and caspase 3 (Fig. 8d) induced by both MBP and $\mathrm{Pyr}$ treatments was significantly reduced in the presence of LV (Fig. 8b and d). Likewise, LV administration also hindered the S-phase cell cycle arrest induced by both MBP and Pyr (Fig. 8e).

Taken together, these data suggest that the antifolate activity could contribute, at least in part, to the antitumor effects of low dose MBP on melanoma cells, i.e. cell death triggering and cell cycle arrest.

\section{Autophagy modulation after Pyrimethamine and Methylbenzoprim treatment}

Available chemotherapeutic agents generally act killing cancer cells by apoptosis whereas drugs inducing autophagy are emerging as able to activate a common pathway of resistance to both standard chemotherapies and novel approaches (e.g. immuno- and targeted therapies) [32]. We have previously reported that autophagy can be modulated by Pyr [33]. Thus, to further compare the effects induced by Pyr and MBP, Mel501 cells were treated with the two antifolate drugs as described above, and then analyzed for autophagy induction. In order to better evaluate the autophagic process, two different assays were used in parallel. First, we used a cationic amphiphilic dye that selectively labels autophagic vacuoles exhibiting bright fluorescence (autophagosome detection by Cyto ID) (Fig. 9a and b) and then we analyzed the LC3-II turn-over by western blot (Fig. 9c and d) The experiments were also performed in the presence or absence of the late autophagy inhibitor $C Q$, [34] which can be used to examine the autophagic flux. Generally, if autophagy is occurring, the amount of LC3-II as well as autophagic vacuoles will be higher in the presence of the inhibitor. As expected, Pyr alone as well as the combined treatment Pyr/CQ led to an increase of autophagosome detection (Fig. 9a and b) and LC3II expression level (Fig. 9c and d). At variance, according to the data reported above, when we treated melanoma cells with CQ in combination with MBP, no significant effects were found, i.e. no significant changes in autophagosome formation as evaluated by Cyto ID detection kit (Fig. 9a and b) or by evaluating LC3II by western blotting (Fig. 9c and d). As autophagy and apoptosis are two stressresponses that are closely interconnected and Pyr was concomitantly able to induce both apoptosis and autophagy, we have also evaluated Pyr-induced apoptosis in the presence of $C Q$. Interestingly, the late autophagy inhibitor CQ significantly enhanced Pyr-induced apoptosis (about 2-folds) (Fig. 9e). In Fig. 9f a representative experiment is shown. Conversely, low dose of MBP 


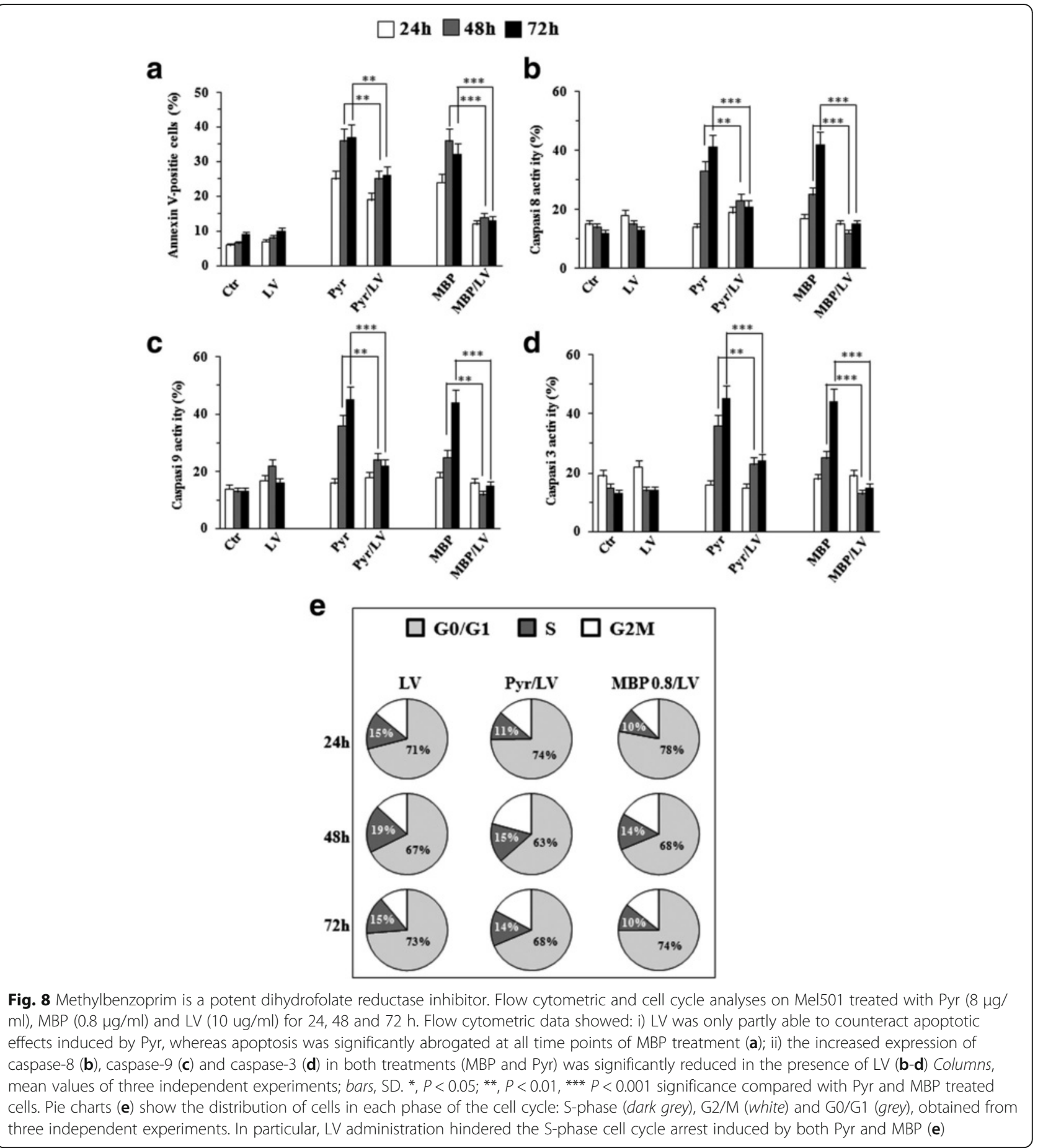

induced a significant increase of apoptotic rate and no effects were observed adding CQ (Fig. 9e and f).

\section{Methylbenzoprim reduces melanoma growth in a SCID mouse model}

The in vivo efficacy of MBP was examined by measuring the reduction of tumor growth in a human melanoma xenograft in severe combined immunodeficiency (SCID) mice. Mel501 melanoma cells were injected into the right flank of SCID mice and at the onset of tumor (when tumors had approximately reached $50 \mathrm{~mm}^{3}$ ), mice were treated with Pyr $(45 \mathrm{mg} / \mathrm{kg})$ or MBP $(12 \mathrm{mg} / \mathrm{kg})$ for 5 days per week up to 40 days from tumor injection for a total 35 days of drug administration. For mice treatments, the doses of Pyr used were selected on the basis of the pharmacokinetic studies carried out in rats 


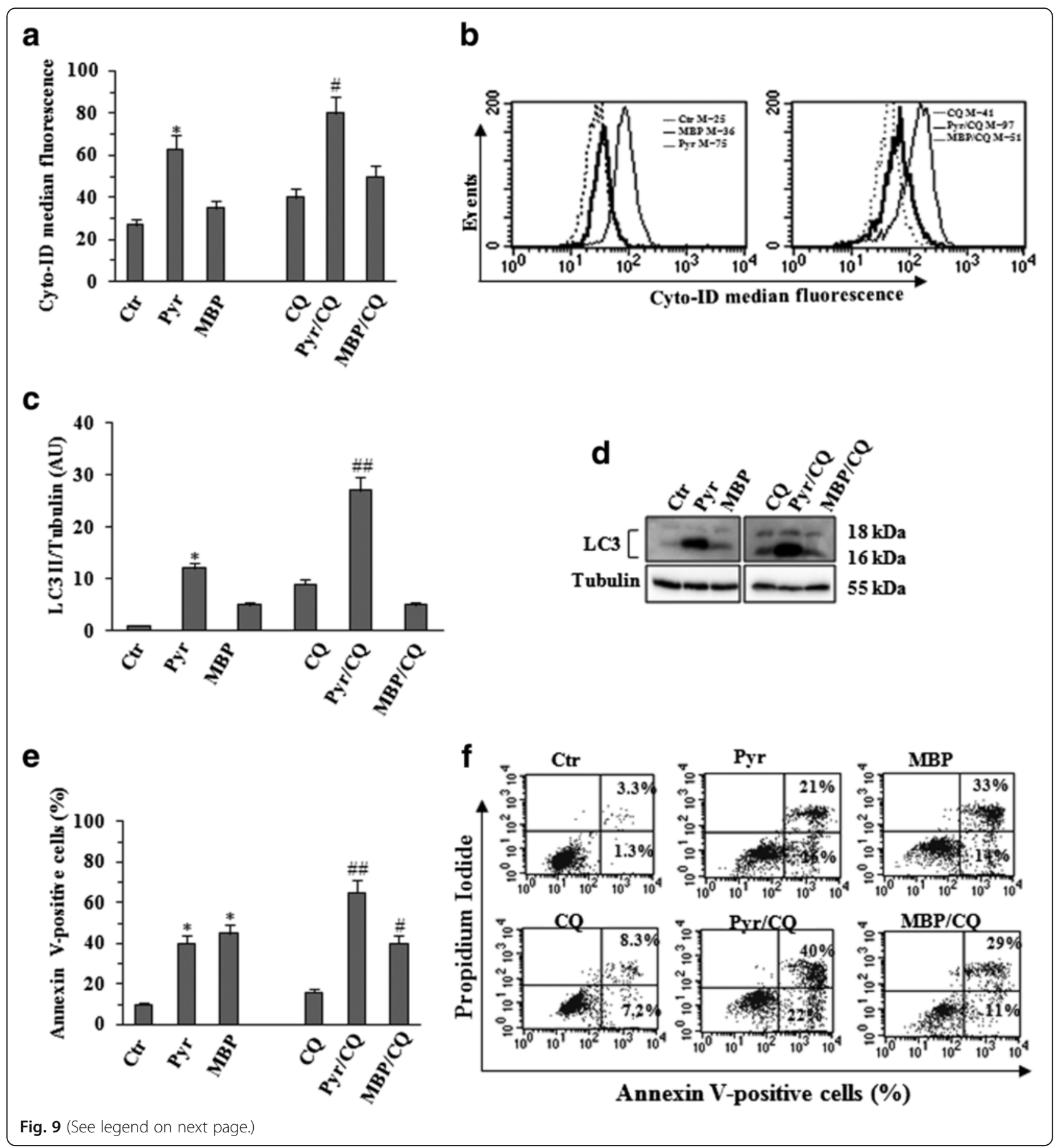




\begin{abstract}
(See figure on previous page.)
Fig. 9 Autophagy modulation after Pyr and MBP treatment. Autophagy was evaluated utilizing two different assays: a cationic amphiphilic dye that selectively labels autophagic vacuoles (Cyto ID autophagy detection kit) by flow cytometric analysis (Fig. 9a-b) and the expression of LC3I/II by WB analysis (Fig. 9c-d). Mel501 melanoma cells were treated with Pyr $(8 \mu \mathrm{g} / \mathrm{ml})$, and MBP $(0.8 \mu \mathrm{g} / \mathrm{ml})$ for $48 \mathrm{~h}$. The experiments were performed in the presence or absence of the late autophagy inhibitor CQ $(10 \mu \mathrm{M})$ for an overnight treatment before the end of the experiment. As shown by fluorescence histograms of Cyto-ID Green autophagy dye (Fig. 9a-b), Pyr treatment was able to induce a significant increase of autophagic vacuoles. Note, the induction of autophagy can be better visualized when the removal of these vesicles is prevented by CQ. Treatment with MBP did not induce significant autophagy and (as expected) CQ treatment (MBP/CQ) did not induce any significant effect. Figure 9a, Columns, mean values of three independent experiments; bars, SD. ${ }^{*}, P<0.05$; significance compared with untreated cells. \#, $P<0.05$; $\# \#, P<0.01$; significance compared with CQ treated cells. In Fig. $9 \mathbf{b}$ the data of a representative experiment were shown. The data were confirmed by western blot of LC3-II turn-over (Fig. 9d) in the presence or absence of CQ. The intensities of bands of LC3II were quantified by densitometric analysis (Fig. 9c). The values were normalized to Tubulin and expressed as arbitrary units (AU). Columns, mean values of three independent experiments; bars, SD. *, $P<0.05$; significance compared with untreated cells. \#, $P<0.05$; \#\#, $P<0.01$; significance compared with CQ treated cells. As Pyr was able to induce both apoptosis and autophagy, we have also evaluated Pyr-induced apoptosis in the presence of CQ. As shown in Fig. 9e, CQ significantly enhanced Pyr-induced apoptosis (about 2-fold) while MBP/CQ treatment did not induce any significant effect. Columns, mean values of three independent experiments; bars, SD. ${ }^{*}, P<0.05$; significance compared with untreated cells. \#, $P<0.05$; \#\#, $P<0.01$; significance compared with CQ treated cells. In Fig. $9 f$ a representative experiment was shown
\end{abstract}

[35] and of our previous work performed in SCID mice [11]. In that work, we have analyzed a wide range of Pyr doses (from 3 to $60 \mathrm{mg} / \mathrm{Kg}$ ). On the basis of these studies the dose of $45 \mathrm{mg} / \mathrm{Kg}$ was considered here [36]. The dose of $45 \mathrm{mg} / \mathrm{kg} / \mathrm{d}$ corresponds to a plasma concentration of $240 \mu \mathrm{mol} / \mathrm{L}$ [37]. In this study, we have also performed preliminary experiments on SCID mice utilizing a range of doses of MBP from 6 to $45 \mathrm{mg} / \mathrm{kg}$ (data not shown). The lowest dose of MBP, which showed antitumor effects comparable to those of Pyr at the dose of $45 \mathrm{mg} / \mathrm{Kg}$, was $12 \mathrm{mg} / \mathrm{kg}$. Of note, the chosen dose of MBP was about three times lower than that of Pyr. Untreated and vehicle treated mice (DMSO) were also included as control groups. Tumor growth was monitored by measuring maximal and minimal diameters by caliper and by evaluating tumor weight, which was estimated as reported elsewhere [11]. In Fig. 10a, the mean of tumor volume at various times after melanoma cell injection is reported. Although a significant reduction of tumor growth $(P<0.05)$ was observed in Pyr treated mice with respect to untreated mice, stronger antitumor effects were obtained with MBP since melanoma grew significantly slower as compared to both vehicle- and Pyrtreatments (Fig. 10a and b). Therefore, MBP exhibits in vivo robust antitumor effects as a lowest dose of this drug than Pyr is sufficient to inhibit more strongly the tumor growth of human melanoma xenograft.

\section{Comparing In vivo effects of Methylbenzoprim and Pyrimethamine}

Tumor growth and treatment with drugs had no effect on the vitality and behavioral responses of animals. No weight loss was observed either during or at the end of the experiment with both treatments. Sacrifice and macroscopic observations of the organs excised from mice at the end of experiments (heart, spleen, kidneys and lungs) showed no macroscopic signs of toxicity in both Pyr and MBP treated groups of mice. Nevertheless, a partially greenish bowel was observed in Pyr-treated mice suggesting a possible occurrence of a blocked bile duct or liver disorders. In order to deepen this aspect, we have further analyzed the liver histologic features of Pyr-treated mice compared to MBP-treated and untreated mice (Fig. 10). As shown in the micrographs (Fig. 10, bottom panels), the liver architecture of Pyrtreated and MBP-treated mice was well preserved and there was no evidence of hepatocyte necrosis or apoptosis.

\section{Discussion}

Successful therapy of metastatic melanoma represents one of the main challenges of chemotherapeutic intervention in the field of cancer control. Although clinical protocols including new biological approaches (e.g. targeted agents, immunotherapy) gave some encouraging results, their efficacy and durable responses remain limited and new evidence indicates their use in combination with chemotherapy $[2,38]$. Thus, the search for novel agents capable of exerting anticancer activity appears to be still mandatory. Of great interest, drug repositioning has been growing in importance in the last few years as, by passing much of the early cost and time needed to bring a drug to market, provides a number of low-cost non-cancer drugs for cancer treatment to be exploited in novel anticancer strategies with high therapeutic potential and low-toxicity [39], allowing also access to cures for a higher population of patients. Among these are antimalarials, a class of compounds that have been proposed as anticancer agents thanks to their antiproliferative activity since 1953 [40]. The reappraisal of one these drugs, Pyr, stems from the encouraging results obtained in the treatment of melanoma and other tumors $[7,8,10,11]$. In addition, Pyr is already used in humans as an orally administered drug for the treatment of infections caused by protozoan parasites. Of note, Pyr belongs to the group of antifolate drugs that blocks the 

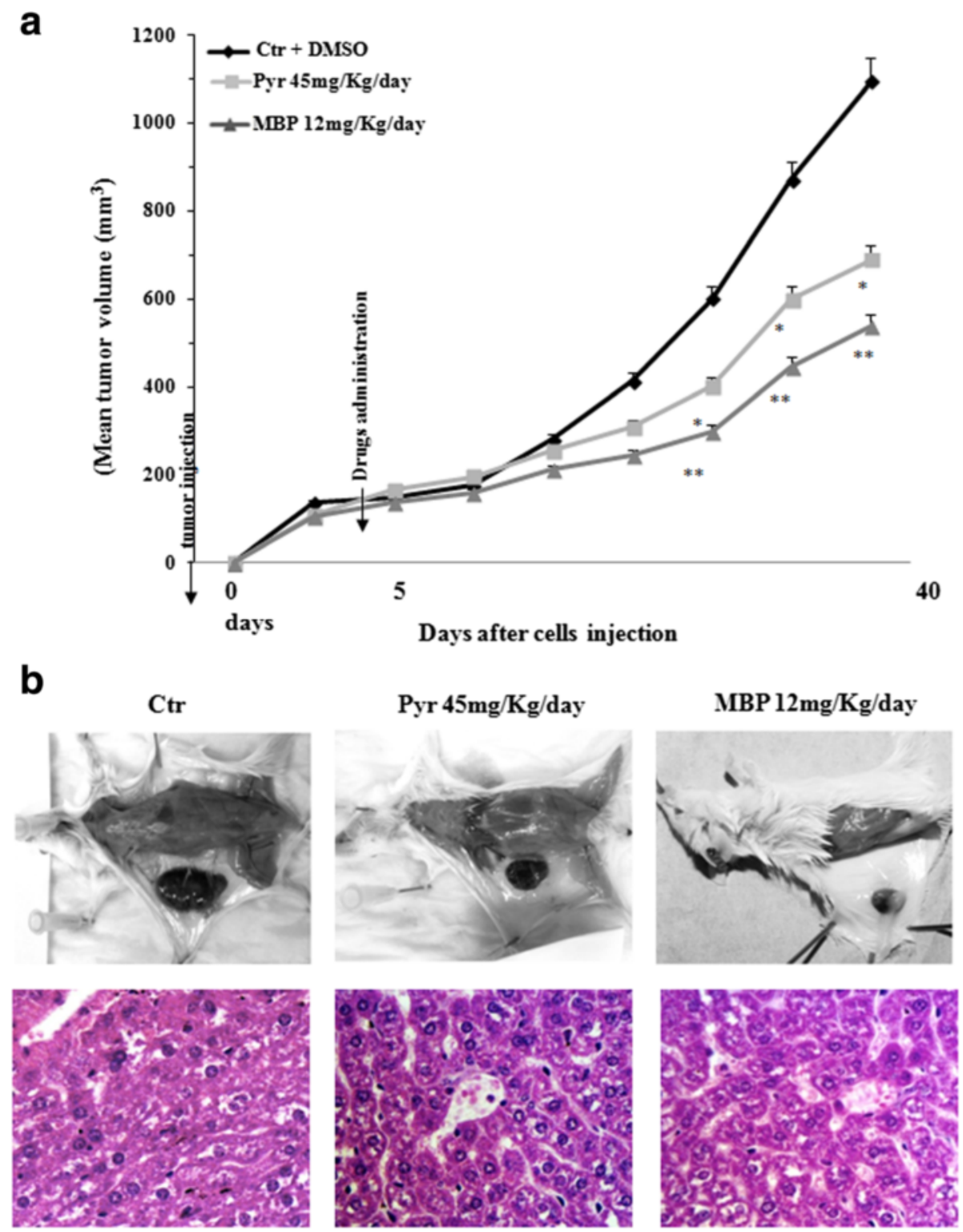

Fig. 10 Methylbenzoprim reduces melanoma growth in a SCID mouse model. Tumor growth features in SCID mice inoculated with the human melanoma cell line Mel501 and treated with vehicle alone or Pyr or MBP by oral gavage. Pyr ( $45 \mathrm{mg} / \mathrm{kg} /$ day) and MBP (12 mg/kg/day) treatments were started at the onset of the metastatic tumor (i.e. $5 \mathrm{~d}$ after melanoma cell injection). The dose of Pyr used to treat mice was chosen on the basis of previous in vivo studies $[11,24]$ whereas the dose of MBP was chosen considering both the results of in vitro and preliminary in vivo experiments. In (a) the mean tumor volume \pm SD at different times after melanoma cell injection is reported. Note the significant values detected in comparison with animals treated with vehicle alone $\left(^{*}\right)=P<0.05 ;\left(^{* *}\right)=P<0.01$. b Upper panels. Micrographs show the difference of tumor size between Pyr and MBP, compared with vehicle alone, when mice were sacrificed. Note, in particular, the significant reduction of tumor size observed with MBP compared vehicle alone. Bottom panels. Liver histologic features of mice treated with vehicle (left), Pyr (middle) and MBP (right). The liver architecture is well preserved. There is no evidence of hepatocyte necrosis or apoptosis, as compared to the control. Staining with Hematoxylin eosin, original magnification 20x

enzyme dihydrofolate reductase (DHFR). DHFR inhibitors have been studied for many years as anticancer agents for their selective toxicity on rapidly dividing cells such as tumor cells. With this in mind, a series of chemically modified analogues of Pyr has been synthesized and screened in the present work. Here, we report for the first time that one of these, MBP, is a valuable candidate for drug repositioning for cancer treatment as it exerts a powerful effect in both in vitro and in vivo on metastatic melanoma via a mechanism partly overlaying that of Pyr. In particular, multiple effects have been detected: i) apoptosis triggering; ii) activation of cysteine 
protease, e.g. cathepsin B, activity; iii) inhibition of cell cycle progression, and iv) inhibition of DHFR activity. Of note, MBP activity results associated with the activation of caspase cascade, as either apical caspase (caspase 8-9) or executioner caspase-3 and with the activity of cathepsin B. Interestingly, this lysosomal cysteine protease has been hypothesized for many years as a further actor in the cell death program execution [41-43]. Concerning the cell cycle, the blocking of S-phase and its progression clearly represent an important cytostatic activity of MBP, as for other anticancer drugs [44]. This property could be of great relevance to develop powerful antitumor combination treatments with drugs able to affect cancer cells in S-phase, such as 5-fluorouracil [45]. In this regard, the inhibition of DHFR, probably at the basis of the block in S-phase, could be of relevance since folates are key determinants of cell proliferation and represent essential targets for the control of cancer cell growth, as it appears for the prototypical DHFR inhibitor methotrexate, which nevertheless is endowed with high toxicity [9]. Most importantly, the dose needed for significant in vivo anticancer activity of MBP appears to be about 5-fold lower than that of Pyr, suggesting that lower doses of MBP could show adequate efficacy and cause minor adverse effects compared to the group of antifolate drugs already in use, such as Pyr and, mainly, methotrexate.

A further key point to be considered in anticancer treatments concerns the shift between cell death and cell survival, sustained by apoptosis and autophagy, respectively. Although the role of autophagy in cancer cells is still controversial, recent studies have established that autophagy can be activated to promote the survival of tumor cells when these are exposed to cellular stress conditions such as, radiation, chemotherapy or targeted agents [46]. Autophagy is thus one of the mechanisms that cancer cells have developed to evade therapyinduced cell death. Apoptosis and autophagy are closely intertwined processes and the shift apoptosis/autophagy is extremely delicate and highly dependent on metabolic interactions [33]. Previously, we reported that Pyr (as TMZ and other chemotherapeutic drugs) is able to induce autophagy at the early stage of treatment of tumor cells $[33,47,48]$. In this context, the Food and Drug Administration (FDA) have currently approved the use of $\mathrm{CQ}$ in combination with conventional therapies to counteract the mechanisms of cell survival in cancer treatment (source http://www.fda.gov). Therefore, based primarily on the ability to inhibit autophagy, CQ and its derivative, hydroxychloroquine, are currently being investigated as adjuvant therapy in multiple clinical trials for cancer treatment [47], leading to their use as potential chemotherapy and radiotherapy sensitizers rather than antineoplastic. In agreement with these findings, when we combined CQ with Pyr, we found an enhanced cytotoxic effect and block of the autophagic flux. In contrast, in our experiments, MBP did not significantly increase autophagy in comparison with baseline levels found in control samples and its combination with $C Q$ did not modify the apoptotic rate of treated cancer cells. Altogether, our data suggest that Pyr could promotes a limited efficacy in vivo, due to its double-edged activity, which induces both apoptotic cell death and autophagy, therefore, limiting its antitumor activity. Conversely, MBP exerts its strong antitumor activity, probably, by stimulating pro-apoptotic effects only [33]. In addition, as already proposed for antimalarial drug Pyr, the strong efficacy of MBP at very low concentrations suggests that the repositioning of these "low-cost drugs" in cancer chemotherapy could be beneficial.

In a near future, the evaluation of the in vitro and in vivo effects of MBP in combination with new melanoma treatment options appears as mandatory. In particular, further understanding of how MBP could interact with immunotherapy and targeted therapy could present an opportunity for treatment of human metastatic melanoma.

\section{Conclusion}

Recent evidence has shown that antimalarial drugs could be beneficial in the treatment of different types of tumors. Among these the DHFR inhibitor Pyrimethamine (Pyr) is a potent pro-apoptotic inducer in cancer cells. Unfortunately, some dose-related adverse effects have been described since Pyr introduction in clinical practice and this weakened the enthusiasm for its anti-cancer activity.

The results of this study led to the identification of a series of Pyrimethamine analogs that were screened for their ability to induce apoptosis in cultured metastatic melanoma cell lines. All screened compounds were able to induce apoptosis, but only one of these was more potent than Pyr. In particular, the compound Methylbenzoprim (MBP) was able to act as an antineoplastic agent in vitro and in vivo, inhibiting melanoma tumor growth at very low concentrations. Our results suggest that MBP could be considered as a novel agent of interest in the development of new therapeutic strategies against metastatic melanoma.

\section{Additional file}

Additional file 1: Figure S.1A and S.1B. Figure S.1A. Representative image of FACS analysis showing activation of caspase 8,9 and 3 in Mel501 melanoma cells treated with Pyr and MBP. Figure S.1B. Representative images of FACS analysis showing activation of caspase 8, 9 and 3 in MeWo melanoma cells treated Pyr and MBP. Figure S.2A. Representative image of FACS analysis showing activation of cathepsin B in Mel501 melanoma cells treated with Pyr and MBP. Figure S.2B.

Representative images of FACS analysis showing activation of cathepsin B in 
MeWo melanoma cells treated with Pyr and MBP. Figure S.3 Representative images of FACS showing cell cycle analysis on Mel501 melanoma cells treated with Pyr and MBP. Note Pyr and MBP hampered cell cycle progression by arresting the cells in S-phase; corresponding decreases of cells in the $G_{1}$ and $G_{2}-M$ phases were also observed. In particular, the low dose of MBP was sufficient to induce a high proportion of S-phase cells, and thereby S-phase arrest, as compared to high dose of Pyr. The formation of a hypodiploid sub-G1 peak (indicative of cell loss due to apoptosis) was also detected confirming the data already evaluated by AV/PI double staining assay. (PPTX $241 \mathrm{~kb})$

\section{Acknowledgments}

Partially supported by AIRC (Associazione Italiana per la Ricerca sul cancro) and by Arcobaleno ONLUS-Fondazione Peretti.

\section{Authors' contributions}

$C T, L G$ and $M A$ performed in vitro experiments and analyzed results; $M B, D M$ and MS carried out in vivo experiments on SCID mice and analyzed results also performing statistical analyses; LG designed the in vivo studies and wrote the manuscript; RJG and BGG configured and synthesized Pyr-analogues; $B C$ and $G D$ were in charge for processing of mice organs histological analyses; WM and AMG designed the study, critically interpreted the results and wrote the manuscript. All authors read and approved the final manuscript.

\section{Competing interests}

The authors declare that they have no competing interests.

\section{Author details}

${ }^{1}$ Department of Therapeutic Research and Medicine Evaluation, Section of Cell Aging and Degeneration, Istituto Superiore di Sanita, 00161 Rome, Italy. ${ }^{2}$ Newcastle Cancer Centre, Northern Institute for Cancer Research, School of Chemistry, Bedson Building, Newcastle University, Newcastle upon Tyne NE1 7RU, UK. ${ }^{3}$ Department of Hematology, Oncology and Molecular Medicine, Istituto Superiore di Sanità, Rome, Italy. ${ }^{4}$ Department of Radiological, Oncological and Pathological Sciences, Sapienza University of Rome, Policlinico Umberto I, Rome, Italy.

\section{Received: 12 April 2016 Accepted: 17 August 2016}

\section{Published online: 06 September 2016}

\section{References}

1. Chiarion Sileni V, Pigozzo J, Ascierto PA, Grimaldi AM, Maio M, Di Guardo L, et al. Efficacy and safety of ipilimumab in elderly patients with pretreated advanced melanoma treated at Italian centres through the expanded access programme. J Exp Clin Cancer Res. 2014;33:30-7.

2. Azijli K, Stelloo E, Peters GJ, Van Den Eertwegh AJ. New developments in the treatment of metastatic melanoma: immune checkpoint inhibitors and targeted therapies. Anticancer Res. 2014;34:1493-505.

3. Ristić-Fira AM, Korićanac LB, Žakula JJ, Valastro LM, lannolo G, Privitera G, et al. Effects of fotemustine or dacarbasine on a melanoma cell line pretreated with therapeutic proton irradiation. J Exp Clin Cancer Res. 2009;28:50-9.

4. Robert C, Thomas L, Bondarenko I, Weber J, Garbe C, Lebbe C, et al. Ipilimumab plus dacarbazine for previously untreated metastatic melanoma. N Engl J Med. 2011;364:2517-26.

5. Maio M, Grob JJ, Aamdal S, Bondarenko I, Robert C, Thomas L, et al. Five-year survival rates for treatment-naive patients with advanced melanoma who received ipilimumab plus dacarbazine in a phase III trial. J Clin Oncol. 2015:33:1191-6.

6. Tatar Z, Thivat E, Planchat E, Gimbergues P, Gadea E, Abrial C. Temozolomide and unusual indications: review of literature. Cancer Treat Rev. 2013;39:125-35.

7. Nilubol N, Zhang L, Shen M, Zhang YQ, He M, Austin CP, et al. Four clinically utilized drugs were identified and validated for treatment of adrenocortical cancer using quantitative high-throughput screening. J Transl Med. 2012;10:198-213.

8. Kundu CN, Das S, Nayak A, Satapathy SR, Das D, Siddharth S. Anti-malarials are anti-cancers and vice versa - one arrow two sparrows. Acta Tropica. 2015;149:1133-27. doi:10.1016/j.actatropica.2015.03.028.
9. Saadat F, Khorramizadeh MR, Mirshafiey A. Chemoprevention by pyrimethamine. Immunopharmacol Immunotoxicol. 2005;27:233-40.

10. Chen M, Osman I, Orlow SJ. Antifolate activity of pyrimethamine enhances temozolomide-induced cytotoxicity in melanoma cells. Mol Cancer Res. 2009;7:703-12.

11. Giammarioli AM, Maselli A, Casagrande A, Gambardella L, Gallina A, Spada $\mathrm{M}$, et al. Pyrimethamine induces apoptosis of melanoma cells via a caspase and cathepsin double-edged mechanism. Cancer Res. 2008;68:5291-300.

12. Waxman S, Herbert V. Mechanisms of pyrimethamine-induced megaloblastosis in human bone marrow. N Engl J Med. 1969;280:1316-9.

13. Matthews JI, Molitor JT, Hunk KK. Pyrimethamine-induced leukopenia and thrombocytopenia in a patient with malaria and tropical sprue: case report. Milit Med. 1973;138:280-3.

14. Opravil M, Keusch G, Lüthy R. Pyrimethamine inhibits renal secretion of creatinine. Antimicrob Agents Chemother. 1993;37:1056-60.

15. Jacobson JM, Davidian M, Rainey PM, Hafner R, Raasch RH, Luft BJ. Pyrimethamine pharmacokinetics in human immunodeficiency viruspositive patients seropositive for Toxoplasma gondii. Antimicrob Agents Chemother. 1996:40:1360-5.

16. Ferone R. Dihydrofolate reductase from pyrimethamine-resistant Plasmodium berghei. J Biol Chem. 1970;245:850-4.

17. Hooft van Huijsduijnen R, Guy RK, Chibale K, Haynes RK, Peitz I, Kelter G, et al. Anticancer properties of distinct antimalarial drug classes. PLoS One. 2013;8:e82962.

18. Pierdominici M, Giammarioli AM, Gambardella L, De Felice M, Quinti I, lacobini $M$, et al. Pyrimethamine (2,4-diamino-5-p-chlorophenyl-6ethylpyrimidine) induces apoptosis of freshly isolated human $T$ lymphocytes, bypassing CD95/Fas molecule but involving its intrinsic pathway. J Pharmacol Exp Ther. 2005;315:1046-57.

19. Kastenbauer U, Wolf E, Kollan C, Hamouda O, Bogner JR, ClinSurv Study Group. Impaired CD4-cell immune reconstitution upon HIV therapy in patients with toxoplasmic encephalitis compared to patients with pneumocystis pneumonia as AIDS indicating disease. Eur J Med Res. 2009;14:244-9.

20. Rehan HS, Chopra D, Kakkar AK. Physician's guide to pharmacovigilance: terminology and causality assessment. Eur J Intern Med. 2009;20:3-8.

21. Clarke JT, Mahuran DJ, Sathe S, Kolodny EH, Rigat BA, Raiman JA, et al. An open-label Phase I/II clinical trial of pyrimethamine for the treatment of patients affected with chronic GM2 gangliosidosis (Tay-Sachs or Sandhoff variants). Mol Genet Metab. 2011;102:6-12.

22. Khan Assir MZ, Ahmad HI, Akram J, Yusuf NW, Kamran U. An outbreak of pyrimethamine toxicity in patients with ischaemic heart disease in Pakistan. Basic Clin Pharmacol Toxicol. 2014;115:291-6.

23. Imran M, Shafi H, Mahmood Z, Sarwar M, Usman HF, Tahir MA, Ashiq MZ. Fatal intoxications due to administration of isosorbide tablets contaminated with Pyrimethamine. J Forensic Sci. 2016. doi:10.1111/1556-4029.13125.

24. Würth R, Thellung S, Bajetto A, Mazzanti M, Florio T, Barbieri F. Drugrepositioning opportunities for cancer therapy: novel molecular targets for known compounds. Drug Discov Today. 2015;15:373-6.

25. Kundu CN, Das S, Nayak A, Satapathy SR, Das D, Siddharth S. Anti-malarials are anti-cancers and vice versa - One arrow two sparrows. Acta Trop. 2015; 149:113-27.

26. Bliss EA, Griffin RJ, Stevens MFG. Structural studies on bio-active compounds. Part 5. Synthesis and properties of 2,4-diaminopyrimidine dihydrofolate reductase inhibitors bearing lipophilic azido groups. J Chem Soc Perkin Trans. 1987:1:2217-28.

27. Griffin RJ, Meek MA, Schwalbe CH, Stevens MFG. Structural studies on bioactive compounds. 8. Synthesis, crystal structure, and biological properties of a new series of 2,4-diamino-5-aryl-6-ethylpyrimidine dihydrofolate reductase inhibitors with in vivo activity against a methotrexate-resistant tumor cell line. J Med Chem. 1989:32:2468-74.

28. Russell PB, Hitchings GH. 2,4-Diaminopyrimidines as antimalarials. III. 5-Aryl derivatives. J Am Chem Soc. 1951;73:3763.

29. Chan LL, Shen D, Wilkinson AR, Patton W, Lai N, Chan E, et al. A novel image-based cytometry method for autophagy detection in living cells. Autophagy. 2012;8:1371-82.

30. Brada M, Judson I, Beale P, Moore S, Reidenberg P, Statkevich P, et al. Phase I dose-escalation and pharmacokinetic study of temozolomide $(\mathrm{SCH}$ 52365) for refractory or relapsing malignancies. Br J Cancer. 1999:81:1022-30.

31. Chow M, Rubin H. Quantitative aspects of the selective killing of transformed cells by methotrexate in the presence of leucovorin. In Vitro Cell Dev Biol Anim. 1999;35:394-402. 
32. Long JS, Ryan KM. New frontiers in promoting tumor cell death: targeting apoptosis, necroptosis and autophagy. Oncogene. 2012;31:5045-60.

33. Giammarioli AM, Gambardella L, Barbati C, Pietraforte D, Tinari A, Alberton M, et al. Differential effects of the glycolysis inhibitor 2-deoxy-D-glucose on the activity of pro-apoptotic agents in metastatic melanoma cells, and induction of a cytoprotective autophagic response. Int J Cancer. 2012;131:E337-47.

34. Klionsky DJ, Abdalla FC, Abeliovich H, Abraham RT, Acevedo-Arozena A, Adeli $\mathrm{K}$, et al. Guidelines for the use and interpretation of assays for monitoring autophagy. Autophagy. 2012;8:445-544.

35. Freund YR, Riccio ES, Phillips SJ, Dousman L, MacGregor JT. Pyrimethamine impairs host resistance to infection with Listeria monocytogenes in BALB/c mice. Toxicol Sci. 1998;42:91-8.

36. Dai C, Zhang B, Liu X, Guo K, Ma S, Cai F. Pyrimethamine sensitizes pituitary adenomas cells to temozolomide through cathepsin B-dependent and caspase-dependent apoptotic pathways. Int J Cancer. 2013;133:1982-93.

37. Klinker $\mathrm{H}$, Langmann P, Richter E. Plasma pyrimethamine concentrations during long-term treatment for cerebral toxoplasmosis in patients with AIDS. Antimicrob Agents Chemother. 1996;40:1623-7.

38. Ma XH, Piao S, Wang D, McAfee QW, Nathanson KL, Lum JJ. Measurements of tumor cell autophagy predict invasiveness, resistance to chemotherapy, and survival in melanoma. Clin Cancer Res. 2011:17:3478-89.

39. Shim JS, Liu JO. Recent advances in drug repositioning for the discovery of new anticancer drugs. Int J Biol Sci. 2014;10:654-63.

40. Myatt AV, Coatney GR, Hernandez T, Burton HW. A further study of the toxicity of pyrimethamine (Daraprim) in man. Am J Trop Med Hyg. 1953;2:1000-1.

41. Wong RS. Apoptosis in cancer: from pathogenesis to treatment. J Exp Clin Cancer Res. 2011;30:87-101.

42. Foghsgaard L, Wissing D, Mauch D, Lademann U, Bastholm L, Boes M. Cathepsin B acts as a dominant execution protease in tumor cell apoptosis induced by tumor necrosis factor. J Cell Biol. 2001;153:999-1010.

43. Werneburg NW, Guicciardi ME, Bronk SF, Kaufmann SH, Gores GJ. Tumor necrosis factor-related apoptosis-inducing ligand activates a lysosoma pathway of apoptosis that is regulated by $\mathrm{BCl}-2$ proteins. J Biol Chem. 2007;282:28960-70.

44. Yadav V, Varshney P, Sultana S, Yadav J, Saini N. Moxifloxacin and ciprofloxacin induces S-phase arrest and augments apoptotic effects of cisplatin in human pancreatic cancer cells via ERK activation. BMC Cancer. 2015;15:581-96

45. Tahmasebi H, Khoshgard K, Sazgarnia A, Mostafaie A, Eivazi MT. Enhancing the efficiency of 5-aminolevulinic acid-mediated photodynamic therapy using 5-fluorouracil on human melanoma cells. Photodiagnosis Photodyn Ther. 2015:S1572-1000:30025-29.

46. Pietrocola F, Izzo V, Niso-Santano M, Vacchelli E, Galluzzi L, Maiuri MC. Regulation of autophagy by stress-responsive transcription factors. Semin Cancer Biol. 2013;23:310-22.

47. Golden EB, Cho HY, Jahanian A, Hofman FM, Louie SG, Schönthal AH. Chloroquine enhances temozolomide cytotoxicity in malignant gliomas by blocking autophagy. Neurosurg Focus. 2014:37:E12.

48. Zhang $X$, Zeng $X$, Liang $X$, Yang $Y$, Li X, Chen $H$. The chemotherapeutic potential of PEG-b-PLGA copolymer micelles that combine chloroquine as autophagy inhibitor and docetaxel as an anti-cancer drug. Biomaterials. 2014;35:9144-54.

\section{Submit your next manuscript to BioMed Central and we will help you at every step:}

- We accept pre-submission inquiries

- Our selector tool helps you to find the most relevant journal

- We provide round the clock customer support

- Convenient online submission

- Thorough peer review

- Inclusion in PubMed and all major indexing services

- Maximum visibility for your research

Submit your manuscript at www.biomedcentral.com/submit

) Biomed Central 